\title{
Metabolism and Nutrition Disorder Class
}

National Cancer Institute

\section{Source}

National Cancer Institute. Metabolism and Nutrition Disorder Class. NCI Thesaurus. Code C49403.

A class of disorders that encompasses conditions occurring as a result of metabolic dysfunction or deviation from the normal nutritional requirements. 